\title{
Effectiveness of Financial Inclusion and Rural Upliftment: Empirical Evidence from Tamil Nadu
}

\author{
Shankar Kumar S*, Jeyaprabha B \\ School of Management, Vel Tech Rangarajan Dr. Sagunthala R\&D Institute of Science and Technology, Chennai, Tamilnadu, India
}

Received October 2, 2021; Revised November 23, 2021; Accepted December 13, 2021

\section{Cite This Paper in the following Citation Styles}

(a): [1] Shankar Kumar S, Jeyaprabha B, "Effectiveness of Financial Inclusion and Rural Upliftment: Empirical Evidence from Tamil Nadu," Universal Journal of Accounting and Finance, Vol. 10, No. 1, pp. 200-210, 2022. DOI: 10.13189/ujaf.2022.100121.

(b): Shankar Kumar S, Jeyaprabha B (2022). Effectiveness of Financial Inclusion and Rural Upliftment: Empirical Evidence from Tamil Nadu. Universal Journal of Accounting and Finance, 10(1), 200-210. DOI: 10.13189/ujaf.2022.100121.

Copyright $\subseteq 2022$ by authors, all rights reserved. Authors agree that this article remains permanently open access under the terms of the Creative Commons Attribution License 4.0 International License

\begin{abstract}
Financial inclusion is the process of confirming access to financial services and adequate credit at timely, wherever required by vulnerable groups such as low income groups and weaker sections at a reasonable cost. Financial inclusion programme primarily emphasizes on offering secured financial solutions to the underprivileged segments of India without any signs of inequality and unbiased treatment. The main objective of the study is to examine the effectiveness of financial inclusion and rural upliftment with empirical evidence from Tamil Nadu. This research study is descriptive in nature, and target audiences are residing in Tamil Nadu region. Secondly, the sample size of this study represents 480 citizens, and the sampling method adopted is non-probability sampling using judgmental sampling method which is used for the target population. The Likert five-point rating scale questions are used for collecting the data through structured questionnaire. The findings revealed that the intensity of financial inclusion has improved over the years across different districts of Tamil Nadu but majority of districts still fall under the medium inclusion in rural area category. In this research study, it is suggested that financial inclusion generates economic progress and prosperity that drive activities among standard of living increasing across all segments of the society. This result shows that financial inclusion programme is potential and capable to transform the face of the state Tamil Nadu and it travels continuously towards upliftment of each and every individual without a doubt. The future research may consider more dimensions of
\end{abstract}

financial inclusion like perception, engagement, empowerment of citizens and comparative study on different financial inclusion schemes at different regions, as this study is restricted to only (rural upliftment) financial inclusion.

Keywords Financial Inclusion, Effectiveness, Empowerment, Rural Upliftment, Tamil Nadu

\section{Introduction}

Financial Inclusion policy was first familiar in India in the year 2005 by the Reserve Bank of India through the release of Annual policy statement. In the year 2005, the report submitted by the Khan committee clearly underlined the uncovered rural poor from the various beneficial schemes offered by professional banking and insurance organizations. It was crystal clear that many poor households in India do not have proper access to various financial services. Either they are not aware of those services offered by financial institutions or even if they are aware, do not have the access to get services at their needs. Financial inclusion is the process of confirming access to financial services and adequate credit at timely, wherever required by vulnerable groups such as low-income groups and weaker sections at a reasonable cost" as stated in the Financial Inclusion committee report submitted by the Rangarajan Committee 
in the year 2008 [12]. Financial inclusion programme primarily emphasizes on offering secured financial solutions to the underprivileged segments of India without any signs of inequality and unbiased treatment [4, 9]. Financial inclusion policies are taken into account by the Government of India and it is identified as financial inclusion which is a growth factor among infrastructure development along with nation's development [1]. Moreover, financial inclusion, financial literacy and the economic development are interrelated with each other [14].

In a modern economy, financial inclusion provides access to financial services and it is a key participation for social inclusion [9]. The modern economy determines the elements based on reliable, efficient, and cost-effective payments [11]. Adoption of new technology becomes a breaking down, critical role and the barriers for both citizens and financial institutions [10].

There are several exclusive financial inclusion schemes that have been introduced by the Government of India. The following schemes are offered to ensure the economics and social security to the underprivileged segment of the nation $[19,5]$.

- Pradhan Mantri Jan Dhan Yojana (PMJDY)

- Pradhan Mantri Mudra Yojana

- Pradhan Mantri Suraksha Bima Yojana (PMSBY)

- Pradhan Mantri Vaya Vandana Yojana

- Atal Pension Yojana (APY)

- Varishtha Pension Bima Yojana (VPBY)

- Stand Up India Scheme

- Sukanya Samriddhi Yojana

- Jeevan Suraksha Bandhan Yojana

- Credit Enhancement Guarantee Scheme (CEGS) for Scheduled Castes (SCs)

- Venture Capital Fund for Scheduled Castes under the Social Sector Initiatives

\subsection{Review of Literature}

The major aim of the financial inclusion scheme is to uplift the poor people and lower-income groups and describe the success of the scheme in few areas or districts in Tamil Nadu [19]. The elements of financial inclusion in the financial services offered by various financial institutions especially banks and other institutions. It enhances the regulators need to take care of the illiterates and the unemployed and they should be offered to play a sufficient role which is needed to financially uplift the economy and also offer a higher standard of living to the citizens of the country [26]. The importance of post offices in financial inclusion plays a vibrant role and they have a wide network in the country that can be used to benefit the rural people. The post offices can be linked with various commercial banks in order to extend their services to all areas especially rural and other backward areas by setting a counter at every post office. [25]. Efficiency of financial inclusion towards various banks and its effects on selected villages based on growth, productive and efficient. The progress of financial inclusion has shown tremendous numbers in terms of account opening. This is a good indicator to continue offering bank services to rural upliftment [17]. There is no doubt that people are in need of various financial services which are offered by the banks. For the services to reach the needed people, banks need to start more branches in rural areas and should offer a complete set of services to satisfy customers. Currently, there is a huge need for banking in rural areas and with the government extending their support the number of banks will be increased in the near future [24]. The lack of access to financial services in few districts have been overcome through banking services and facilities need to be extended properly to those areas for the country's development [18]. The extension of the bank is directly proportional to rural upliftment. If the banks perform well, then automatically the lower-income group will have a better life since they will use these banks for their upliftment [20]. Financial inclusion witnessed that they perform reasonably well across all the parameters but they lack some vital things like proper education, training skill and other such things [23].

The easy accessibility of finance for the betterment of the poor and vulnerable groups is very important. The government has taken enough efforts to ensure that the poor people get enough access to the financial system which is made possible by opening banks in most rural areas. India's fastest growing economy is only possible due to inclusion based on accessibility, availability and usage [21]. Financial behaviour of rural and urban people towards the various financial schemes brings the usage pattern of populations to differ in their activities in which they are accessing financial services and the degree of usage towards different financial portfolios. On the whole, there is some similarity between two groups though they differ in some parameters [22]. Financial inclusion is in progressive stage in India and is trying major efforts towards rural inclusive growth but there is a necessity for the Government of India to concentrate and promote it to citizens of the nation [27].

Various financial institutions adjoining the government have taken a wide range of initiatives to develop necessary infrastructure to facilitate the financial inclusion programme to the rural people [24]. The financial inclusion programme enlightens the financial decisions of the rural people and empowers them to invest their savings in appropriate platforms [18]. It will lead the government to consolidate the savings and ensure its multiple usage and ends with 'social inclusion' [5]

\subsection{Research Gap}

The Research Gap identified that stakeholders are having an important role in (Citizen) participating and (Government) executing the financial inclusion 
programme in rural upliftment which is recognized through the existing research [13]. Few individuals don't know about the financial inclusion programme but they are aware of selected schemes in the financial inclusion programme [19]. But there is very few research that examines the effectiveness of financial inclusion programme in rural upliftment. This study is important to examine and confirm the effectiveness of financial inclusion programme in rural upliftment. This research provides an insight to policy makers, as the study examines the relationship between Awareness of Financial Inclusion (AFI), Access and Usage of Financial Inclusion (AUFI), Challenges of Financial Inclusion (CFI), Impact of Financial Literacy (IFL) and Causes of Financial Exclusion (CFE) among Effectiveness of Financial Inclusion (EFI). The right decision on implementation of Financial Inclusion programme will build the new beginnings for Rural Empowerment or Upliftment and Incredible India [15].

\subsection{Research Objectives}

To overcome the research gap, the following objectives have been formulated:
To study the salient features of various financial inclusion programmes offered to the rural people.

- To understand the level of utilization of each scheme under the financial inclusion programme among the rural people.

- To identify the factors hindrance to the reach of the financial inclusion programme to the rural people.

- To analyse the Socio-Demographic Profile of the rural Participants using financial Inclusion Programme.

\section{Material and Methods}

\subsection{Research Design and Paradigm}

This research applied descriptive research in nature [2, $6,7]$. The present research measures the effectiveness of financial inclusion and rural upliftment with empirical evidence from Tamil Nadu. The structured questionnaire method is applied to this study [6]. From this study, rural upliftment can be decided as where, when and how the effectiveness of financial inclusion programme in Tamilnadu region is travelling.

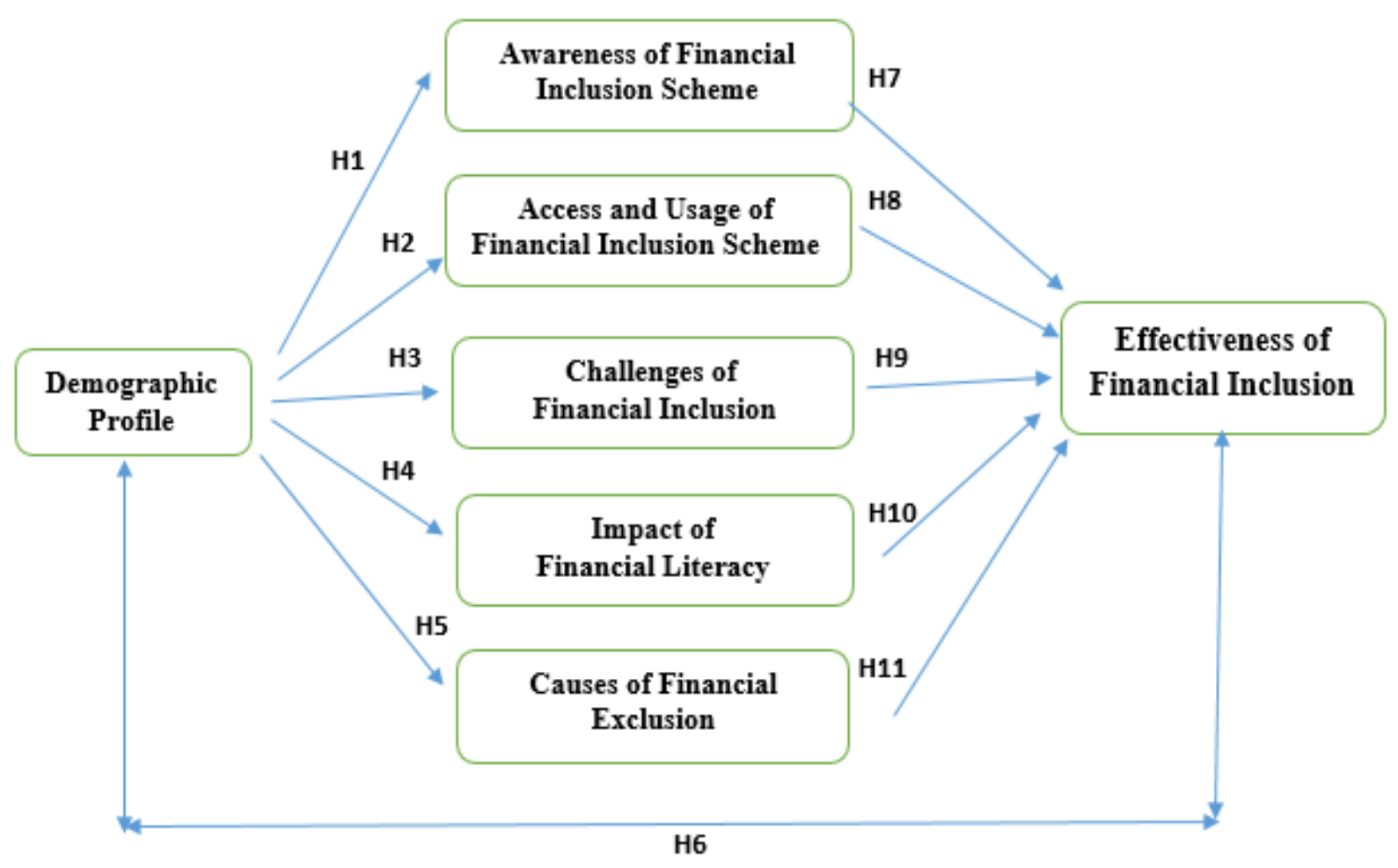

Figure 1. Research Framework 
Table 1. Hypothesis Framework

\begin{tabular}{|c|c|c|}
\hline $\begin{array}{l}\text { Independent } \\
\text { Sample T } \\
\text { Test }\end{array}$ & \multirow{3}{*}{ H1-H6 } & $\begin{array}{l}\text { There is a significant difference between male and female with respect to Financial Inclusion Awareness, } \\
\text { Access and Usage, Challenges, Impact of financial literacy, Causes of Financial Exclusion and Effectiveness } \\
\text { of Financial Inclusion. }\end{array}$ \\
\hline $\begin{array}{l}\text { One Way } \\
\text { ANOVA }\end{array}$ & & $\begin{array}{l}\text { There is a significant difference among Demographic Profile with respect to Financial Inclusion Awareness, } \\
\text { Access and Usage, Challenges, Impact of financial literacy, Causes of Financial Exclusion and Effectiveness } \\
\text { of Financial Inclusion }\end{array}$ \\
\hline Chi Square & & $\begin{array}{l}\text { There is an association between Demographic Profile and Financial Inclusion Awareness, Access and Usage, } \\
\text { Challenges, Impact of financial literacy, Causes of Financial Exclusion and Effectiveness of Financial } \\
\text { Inclusion. }\end{array}$ \\
\hline \multirow{5}{*}{$\begin{array}{l}\text { Multiple } \\
\text { Linear } \\
\text { Regression }\end{array}$} & $\mathrm{H} 7$ & $\begin{array}{l}\text { Awareness of Financial Inclusion (AFI) Scheme has a significant influence on Effectiveness of Financial } \\
\text { Inclusion (EFI). }\end{array}$ \\
\hline & H8 & $\begin{array}{l}\text { Access and Usage of Financial Inclusion (AUFI) Scheme has a significant influence on Effectiveness of } \\
\text { Financial Inclusion (EFI). }\end{array}$ \\
\hline & H9 & $\begin{array}{l}\text { Challenges of Financial Inclusion (CFI) has a significant influence on Effectiveness of Financial Inclusion } \\
\text { (EFI). }\end{array}$ \\
\hline & H10 & Impact of financial literacy (IFL) has a significant influence on Effectiveness of Financial Inclusion (EFI). \\
\hline & H11 & Causes of Financial Exclusion (CFE) has a significant influence on Effectiveness of Financial Inclusion (EFI). \\
\hline
\end{tabular}

\subsection{Target Population, Sample Size and Sampling Technique}

This research is conducted by adopting Non-probability sampling, but not all citizens of the population have equal participation in the study. As this study was directed using judgmental sampling, only the researcher selects citizen based on the subjective judgement of the researcher rather than random selection [16].

The Formulae for sample size determination is $\mathrm{N}=$ $\left(\mathrm{z}^{2 *} \mathrm{p} * \mathrm{q}\right) / \mathrm{S} . \mathrm{E}^{2}$; In this study $95 \%$ confidence interval is chosen,

- $\mathrm{Z}$ - represents the $\mathrm{z}$ value for the corresponding confidence interval as 1.96

- $\quad \mathrm{P}$ - represents probability of occurrence of an event (50\%) is unknown it is assumed to be 0.5

- $\mathrm{q}$ - represents probability of non-occurrence of the event $(\mathrm{Q}=100-\mathrm{P})$

- S.E. is the desired margin of error (acceptable sample error) as $+/-5$ percent of the true value

Hence, the sample size is calculated as, $\mathrm{N}=(1.96 *$ $1.96 * 0.5 * 0.5) /(0.05 * 0.05)=384.16$

Hence, the desired sample size is at least 385 for this research. This study was conducted with 500 participants and after data cleaning 480 responses have been finalized for analysis [3]. The target population contains citizens residing in Tamilnadu. Our unit of analysis is the Citizens of Tamilnadu and they are considered as a source of knowledge hub and more aware of the financial inclusion.

\subsection{Sources of Data Collection}

This research study uses both the primary data and secondary data for understanding the effectiveness of financial inclusion and rural upliftment with empirical evidence from Tamil Nadu.

- Primary Data: Structured Questionnaire and survey method $[7,6,8]$.
- Secondary Data: Internet sources, research articles, publications, journals and magazines [6, 8].

\subsection{Instrument Development}

The research was made on a sample of 480 respondents using both dichotomous questions, and Likert five-point rating scale using a structured and close-ended questionnaire were framed. The research questions are used to collect the data through structured questionnaire valued on a Likert 5-point ranking scale ranging from 1 (Strongly Disagree) - 5 (Strongly Agree) [3, 16]. The questionnaire is divided based on six parts for convenience of data collection:

- The first part includes Awareness of Financial Inclusion Scheme (AFI).

- The second part represents the Access and Usage of Financial Inclusion Scheme (AUFI).

- The third part focuses on Challenges of Financial Inclusion (CFI).

- The fourth part contains Impact of financial literacy (IFL).

- The fifth part represents the Causes of Financial Exclusion (CFE).

- The sixth part includes Socio-Demographic Profile.

\subsection{Methods of Data Analysis}

The statistical tool used in this research as Descriptive Analysis, Pearson Correlation, Independent Sample T-Test, Anova and Multiple Linear Regression Analysis [6]. The analysis is carried out by using IBM SPSS [7].

\section{Results and Discussion}

The results of the research reveal the effectiveness of financial inclusion programme in rural upliftment. The 
data was analyzed using Descriptive Analysis, Pearson Correlation, Reliability Test, Independent Sample T-Test, Anova and Multiple Linear Regression Analysis was performed to test the hypothesis under consideration.

\subsection{Socio-Demographic Profile of the Participants}

Table 2. Socio-Demographic Profile of the Survey Participants $(\mathrm{N}=$ 480)

\begin{tabular}{|c|c|c|c|}
\hline Parameter & Target Audience & $\begin{array}{c}\text { Sample } \\
\text { size }\end{array}$ & $\%$ \\
\hline \multirow{2}{*}{ Gender } & Male & 328 & $68.3 \%$ \\
\hline & Female & 152 & $31.7 \%$ \\
\hline \multirow{4}{*}{ Age } & Below 25 Years & 120 & $25 \%$ \\
\hline & 26-45Years & 131 & $27.3 \%$ \\
\hline & 46-60Years & 127 & $26.5 \%$ \\
\hline & 61 Years Above & 102 & $21.2 \%$ \\
\hline \multirow{4}{*}{$\begin{array}{l}\text { Education } \\
\text { Qualification }\end{array}$} & High School & 107 & $22.3 \%$ \\
\hline & Under Graduation & 131 & $27.3 \%$ \\
\hline & Post-Graduation & 98 & $20.4 \%$ \\
\hline & Professionals & 144 & $30 \%$ \\
\hline \multirow{5}{*}{ Annual Income } & Below 1,50,000 & 81 & $16.9 \%$ \\
\hline & $1,50,001-2,50,000$ & 105 & $21.9 \%$ \\
\hline & $2,50,001-3,50,000$ & 116 & $24.2 \%$ \\
\hline & $3,50,001-4,50,000$ & 68 & $14.2 \%$ \\
\hline & Above 4,50,000 & 110 & $22.8 \%$ \\
\hline \multirow{4}{*}{ Occupation } & Salaried & 142 & $29.6 \%$ \\
\hline & Self-employed & 194 & $40.4 \%$ \\
\hline & Professional & 130 & $27.1 \%$ \\
\hline & Unemployed & 14 & $2.9 \%$ \\
\hline
\end{tabular}

As revealed in Table 2, Data was taken from 480 respondents in Tamil Nadu. Table consist of Socio-Demographic Profile like gender, age, education qualification, annual income and occupation of respondents. Results specify that around 328 male which equals to $68.3 \%$ while 152 were female members showing $31.7 \%$ of the total respondents. The aggregate outcome of
Age Category; 22.3\% members were under Below 25 Years which reveals the most minimal rate among all others. Around $27.3 \%$ respondents were between 26-45Years, 26.5\% were between $46-60$ years and $21.2 \%$ members whose ages were 61 Years Above. Education Qualification matrix of respondents demonstrates that 22.3\% respondents were having High School education, 27.3\% were equivalent to Under Graduation, 20.4\% having the education equal to Post-Graduation which validates the most reduced rate among others and 30\% respondents are having capability equal to Professionals education.

Annual income matrix confirms the income range of respondents. It exhibits $16.9 \%$ members are salary was not closely or equivalent to Below Rs. 1,50,000, 21.9\% respondents gained between Rs. 1,50,001 - 2,50,000, $24.2 \%$ respondents earned between Rs. 2,50,001 $3,50,000$ most elevated rate among all, $14.2 \%$ respondents gain Rs. 3,50,001 - 4,50,000, which demonstrates reduced rate among others. $22.8 \%$ respondents gain above Rs. $4,50,000$ or above. Occupation matrix of respondents exhibits that $29.6 \%$ respondents were Salaried Category, $40.4 \%$ were equivalent to Self-employed Category higher rate among all, 27.1\% having the Professional Category which proves the most reduced rate among others and $2.9 \%$ respondents were equivalent to Unemployed Category which delivers the low rate among all others.

\subsection{Correlation and Reliability Result}

Correlation coefficient results and Reliability results are given in Table 2. The Reliability analysis is executed using Cronbach alpha test and the value for Awareness of Financial Inclusion (AFI) is 0.884, Access and Usage of Financial Inclusion (AUFI) is 0.816, Challenges of Financial Inclusion (CFI) is 0.771, Impact of Financial Literacy (IFL) is 0.808, Causes of Financial Exclusion (CFE) is 0.795 and Effectiveness of Financial Inclusion (EFI) is 0.762 which is above 0.7 . This reliability value shows that the variables included in this study possess the desirable internal consistency needed for further analysis.

Table 3. Correlation Matrix for the Outcome of Financial Inclusion

\begin{tabular}{|c|c|c|c|c|c|c|}
\hline Variables & 1 & 2 & 3 & 4 & 5 & 6 \\
\hline 1. Awareness of Financial Inclusion (AFI) & 1 & & & & & \\
\hline 2. Access and Usage of Financial Inclusion (AUFI) & -.027 & 1 & & & & \\
\hline 3. Challenges of Financial Inclusion (CFI) & -.026 & $.660^{* *}$ & 1 & & & \\
\hline 4. Impact of Financial Literacy (IFL) & -.058 & $.489 * *$ & $.585^{* *}$ & 1 & & \\
\hline 5. Causes of Financial Exclusion (CFE) & -.036 & $.550 * *$ & $.625^{* *}$ & $.687 * *$ & 1 & \\
\hline 6. Effectiveness of Financial Inclusion (EFI) & -.009 & $.708^{* *}$ & $.904 * *$ & $.682^{* *}$ & $.650 * *$ & 1 \\
\hline Mean & 15.74 & 44.30 & 23.67 & 19.88 & 28.00 & 24.14 \\
\hline Standard Deviation & 1.634 & 5.614 & 3.877 & 2.958 & 4.206 & 3.625 \\
\hline Cronbach's Alpha Reliability & 0.884 & 0.816 & 0.771 & 0.808 & 0.795 & 0.762 \\
\hline
\end{tabular}

\footnotetext{
**. Correlation is significant at the 0.01 level (2-tailed).
} 
All the correlation results are positive at significance level of $0.01 \quad(\mathrm{p}<0.01)$. The Awareness of Financial Inclusion (AFI) having negative relationship on Access and Usage of Financial Inclusion (AUFI) is (-.027), Challenges of Financial Inclusion (CFI) is (-.026), Impact of Financial Literacy (IFL) is (-.058), Causes of Financial Exclusion (CFE) is (-.036) and Effectiveness of Financial Inclusion (EFI) is (-.009) at respectively. The correlation results between Access and Usage of Financial Inclusion (AUFI) proposed that the moderate positive relationship between Challenges of Financial Inclusion (CFI) is (.660), Impact of Financial Literacy (IFL) is (.489), Causes of Financial Exclusion (CFE) is (.550) and the Effectiveness of Financial Inclusion (EFI) having strong positive relationship at 0.708 on Access and Usage of Financial Inclusion.

The correlation among Challenges of Financial Inclusion proposed that the moderate positive relationship between Impact of Financial Literacy (IFL) is (.585), Causes of Financial Exclusion (CFI) is (.625) and the Effectiveness of Financial Inclusion has strong positive relationship at 0.904 on Challenges of Financial Inclusion. In terms of correlation between Impact of Financial Literacy proposed that the moderate positive relationship between Causes of Financial Exclusion (.687) and Effectiveness of Financial Inclusion (EFI) is (.682). As well as the value of correlation between Causes of
Financial Exclusion (CFE) is and Effectiveness of Financial Inclusion $(\mathrm{EFI})$ is $(\mathrm{r}=0.650, \mathrm{p}<0.01)$ which proves that there is a direct positive relationship among them.

\subsection{Independent-Sample $T$ Test}

We analysed six dimensions: (i) Awareness of Financial Inclusion (AFI); (ii) Access and Usage of Financial Inclusion (AUFI); (iii) Challenges of Financial Inclusion (CFI); (iv) Impact of Financial Literacy (IFL); (v) Causes of Financial Exclusion (CFE); and (vi) Effectiveness of Financial Inclusion (EFI) using Independent Samples T Test (Table 4).

From table 4, it is observed that $\mathrm{P}$ value is lower than the 0.05 in that null hypothesis is rejected at $5 \%$ level. Hence, there is significance difference between male and female on Access and Usage of Financial Inclusion (AUFI) and Impact of Financial Literacy (IFL). There is no significance difference between male and female with regard to Awareness of Financial Inclusion (AFI), Challenges of Financial Inclusion (CFI), Causes of Financial Exclusion (CFE) and Effectiveness of Financial Inclusion (EFI), since $\mathrm{P}$ value is greater than 0.05 . Hence the null hypothesis is accepted at $5 \%$ level with regard to Awareness of Financial Inclusion (AFI), Challenges of Financial Inclusion (CFI), Causes of Financial Exclusion (CFE) and Effectiveness of Financial Inclusion (EFI).

Table 4. Independent-Sample $\mathrm{T}$ Test for Difference between Male and Female with respect to Financial Inclusion Awareness, Access and Usage, Challenges, Impact of financial literacy, Causes of Financial Exclusion and Effectiveness of Financial Inclusion

\begin{tabular}{|c|c|c|c|c|c|c|}
\hline \multirow{2}{*}{ Scale } & \multicolumn{2}{|c|}{ Male $(\mathrm{N}=328)$} & \multicolumn{2}{|c|}{ Female $(\mathrm{N}=152)$} & \multirow{2}{*}{$\mathbf{T}$} & \multirow{2}{*}{$\mathbf{P}$} \\
\hline & Mean & S.D & Mean & S.D & & \\
\hline Awareness of Financial Inclusion (AFI) & 15.71 & 1.66 & 15.80 & 1.57 & 0.761 & 0.383 \\
\hline Access and Usage of Financial Inclusion (AUFI) & 44.62 & 5.42 & 43.63 & 5.5 & 3.511 & $0.047 *$ \\
\hline Challenges of Financial Inclusion (CFI) & 23.74 & 3.78 & 23.54 & 4.08 & 0.525 & 0.469 \\
\hline Impact of Financial Literacy (IFL) & 19.91 & 2.82 & 19.83 & 3.20 & 4.190 & $0.041^{*}$ \\
\hline Causes of Financial Exclusion (CFE) & 28.08 & 4.18 & 27.80 & 4.26 & 0.080 & 0.777 \\
\hline Effectiveness of Financial Inclusion (EFI) & 24.19 & 3.55 & 24.03 & 3.78 & 0.544 & 0.461 \\
\hline
\end{tabular}


Table 5. One Way Anova for Demographic Profile and Financial Inclusion Awareness, Access and Usage, Challenges, Impact of financial literacy, Causes of Financial Exclusion and Effectiveness of Financial Inclusion

\begin{tabular}{|c|c|c|c|}
\hline Demographic Profile & Scale & $\mathbf{F}$ & $\mathbf{P}$ \\
\hline \multirow{6}{*}{ Age } & Awareness of Financial Inclusion (AFI) & .071 & .975 \\
\hline & Access and Usage of Financial Inclusion (AUFI) & .501 & .682 \\
\hline & Challenges of Financial Inclusion (CFI) & .261 & .853 \\
\hline & Impact of Financial Literacy (IFL) & 1.225 & .300 \\
\hline & Causes of Financial Exclusion (CFE) & .616 & .605 \\
\hline & Effectiveness of Financial Inclusion (EFI) & .384 & .765 \\
\hline \multirow{6}{*}{ Qualification } & Awareness of Financial Inclusion (AFI) & .989 & .398 \\
\hline & Access and Usage of Financial Inclusion (AUFI) & .419 & .740 \\
\hline & Challenges of Financial Inclusion (CFI) & .310 & .818 \\
\hline & Impact of Financial Literacy (IFL) & .695 & .555 \\
\hline & Causes of Financial Exclusion (CFE) & .400 & .753 \\
\hline & Effectiveness of Financial Inclusion (EFI) & .653 & .581 \\
\hline \multirow{6}{*}{ Annual Income } & Awareness of Financial Inclusion (AFI) & 1.353 & .249 \\
\hline & Access and Usage of Financial Inclusion (AUFI) & 1.332 & .257 \\
\hline & Challenges of Financial Inclusion (CFI) & 1.147 & .334 \\
\hline & Impact of Financial Literacy (IFL) & .931 & .445 \\
\hline & Causes of Financial Exclusion (CFE) & .682 & .605 \\
\hline & Effectiveness of Financial Inclusion (EFI) & 1.158 & .329 \\
\hline \multirow{6}{*}{ Occupation } & Awareness of Financial Inclusion (AFI) & 1.914 & .126 \\
\hline & Access and Usage of Financial Inclusion (AUFI) & 1.349 & .258 \\
\hline & Challenges of Financial Inclusion (CFI) & 4.043 & $.007 * *$ \\
\hline & Impact of Financial Literacy (IFL) & 1.237 & .296 \\
\hline & Causes of Financial Exclusion (CFE) & 1.383 & .247 \\
\hline & Effectiveness of Financial Inclusion (EFI) & 2.192 & .088 \\
\hline
\end{tabular}

\subsection{One Way ANOVA}

ANOVA is a statistical analysis used for the hypothesis testing. There is no significant difference between two or more population means. Here one way ANOVA is used to examine significant differences among age category.

There is no significant difference among the Age group, Qualification and Annual Income with respect to Awareness of Financial Inclusion (AFI), Access and Usage of Financial Inclusion (AUFI), Challenges of Financial Inclusion (CFI), Impact of Financial Literacy (IFL), Causes of Financial Exclusion (CFE) and Effectiveness of Financial Inclusion (EFI), Since P value is greater than 0.05 . Hence, null hypothesis is accepted at 5\% level with respect to Awareness of Financial Inclusion (AFI), Access and Usage of Financial Inclusion (AUFI), Challenges of Financial Inclusion (CFI), Impact of Financial Literacy (IFL), Causes of Financial Exclusion
(CFE) and Effectiveness of Financial Inclusion (EFI).

Since $\mathrm{P}$ value is less than 0.01 , null hypothesis is rejected at $1 \%$ level with regard to occupation level and Challenges of Financial Inclusion (CFI). Hence, there is a significant difference among occupation level with respect to Challenges of Financial Inclusion (CFI). There is no significant difference among the occupation level with respect to Awareness of Financial Inclusion (AFI), Access and Usage of Financial Inclusion (AUFI), Impact of Financial Literacy (IFL), Causes of Financial Exclusion (CFE) and Effectiveness of Financial Inclusion (EFI). Since $\mathrm{P}$ value is greater than 0.05 . Hence, null hypothesis is accepted at 5\% level with respect to Awareness of Financial Inclusion (AFI), Access and Usage of Financial Inclusion (AUFI), Impact of Financial Literacy (IFL), Causes of Financial Exclusion (CFE) and Effectiveness of Financial Inclusion (EFI). 
Table 6. Chi-Square Test Value for Various Variables

\begin{tabular}{|c|c|c|c|c|}
\hline S. No & Variable & Chi-Square value & Sig. Value & Significance or not \\
\hline \multicolumn{5}{|c|}{ Demographic Profile Vs Awareness of Financial Inclusion } \\
\hline 1 & Gender & 0.147 & 0.307 & Not Significant \\
\hline 2 & Age & 0.180 & 0.952 & Not Significant \\
\hline 3 & Qualification & 0.201 & 0.818 & Not Significant \\
\hline 4 & Annual Income & 0.293 & 0.139 & Not Significant \\
\hline 5 & Occupation & 0.402 & $0.043^{*}$ & Significant \\
\hline \multicolumn{5}{|c|}{ Demographic Profile Vs Access and Usage of Financial Inclusion } \\
\hline 1 & Gender & 0.227 & 0.523 & Not Significant \\
\hline 2 & Age & 0.419 & $0.041^{*}$ & Significant \\
\hline 3 & Qualification & 0.374 & 0.591 & Not Significant \\
\hline 4 & Annual Income & 0.450 & 0.197 & Not Significant \\
\hline 5 & Occupation & 0.413 & $0.049^{*}$ & Significant \\
\hline \multicolumn{5}{|c|}{ Demographic Profile Vs Challenges of Financial Inclusion } \\
\hline 1 & Gender & 0.387 & $0.006^{* *}$ & Highly Significant \\
\hline 2 & Age & 0.316 & 0.500 & Not Significant \\
\hline 3 & Qualification & 0.290 & 0.831 & Not Significant \\
\hline 4 & Annual Income & 0.327 & 0.891 & Not Significant \\
\hline 5 & Occupation & 0.323 & 0.409 & Not Significant \\
\hline \multicolumn{5}{|c|}{ Demographic Profile Vs Impact of Financial Literacy } \\
\hline 1 & Gender & 0.127 & 0.856 & Not Significant \\
\hline 2 & Age & 0.302 & 0.152 & Not Significant \\
\hline 3 & Qualification & 0.345 & $0.006^{* *}$ & Highly Significant \\
\hline 4 & Annual Income & 0.302 & 0.624 & Not Significant \\
\hline 5 & Occupation & 0.241 & 0.864 & Not Significant \\
\hline \multicolumn{5}{|c|}{ Demographic Profile Vs Causes of Financial Exclusion } \\
\hline 1 & Gender & 0.459 & $0.018^{*}$ & Significant \\
\hline 2 & Age & 0.365 & 0.112 & Not Significant \\
\hline 3 & Qualification & 0.292 & 0.929 & Not Significant \\
\hline 4 & Annual Income & 0.361 & 0.726 & Not Significant \\
\hline 5 & Occupation & 0.320 & 0.661 & Not Significant \\
\hline \multicolumn{5}{|c|}{ Demographic Profile Vs Effectiveness of Financial Inclusion } \\
\hline 1 & Gender & 0.147 & 0.837 & Not Significant \\
\hline 2 & Age & 0.317 & 0.262 & Not Significant \\
\hline 3 & Qualification & 0.371 & $0.005^{* *}$ & Highly Significant \\
\hline 4 & Annual Income & 0.337 & 0.563 & Not Significant \\
\hline 5 & Occupation & 0.358 & $0.018^{*}$ & Significant \\
\hline
\end{tabular}

\subsection{Chi-Square}

At 5\% significance level, Awareness of Financial Inclusion (AFI) are strongly associated with Occupation but gender, age, qualification and annual income do not show any significant association with variables of Awareness of Financial Inclusion (AFI). Access and Usage of Financial Inclusion (AUFI) by respondents are having strong association with the age and occupation but gender, qualification and annual income are not showing significant association with variables of Access and Usage of Financial Inclusion (AUFI). At 1\% significance level, Challenges of Financial Inclusion (CFI) are strongly associated with gender but age, qualification, occupation and annual income are not showing significant association with variables of Challenges of Financial Inclusion (CFI). 
At 1\% significance level, Impact of Financial Literacy (IFL) are strongly associated with qualification but gender, age, occupation and annual income do not show significant association with variables of Impact of Financial Literacy (IFL).

At 5\% significance level, Causes of Financial Exclusion (CFE) are strongly associated with gender but occupation, age, qualification and annual income do not show significant association with variables of Causes of Financial Exclusion (CFE). Hence, Effectiveness of Financial Inclusion (EFI) are strongly associated with qualification (1\% significance level) and Occupation (5\% significance level) but gender, age and occupation do not show significant association with variables of Effectiveness of Financial Inclusion (EFI).

\subsection{Multiple Linear Regression}

The Multiple Linear Regression (MLR) analysis is a simple extension of linear regression and it is used to establish linear relationships, in which the dependent variable $\mathrm{Y}$ is tested against a set of two or more independent variable.
Table 7 specifies the end result of $\mathrm{R}$ Square is 0.865 and dependent variable is Effectiveness of Financial Inclusion (EFI) which can be described by five independent variables: Awareness of Financial Inclusion (AFI), Access and Usage of Financial Inclusion (AUFI), Challenges of Financial Inclusion (CFI), Impact of Financial Literacy (IFL) and Causes of Financial Exclusion (CFE) by $86.5 \%$ at 0.05 significance level. The $\mathrm{p}$-value of three independent variables (Access and Usage of Financial Inclusion (AUFI), Challenges of Financial Inclusion (CFI) and Impact of Financial Literacy (IFL) variables) are less than 0.05 , which means that the independent variables have a statistically significant impact on the dependent variable, hence H8, H9 and H10 are supported.

However, the p-value of two independent variables (Awareness of Financial Inclusion (AFI) and Causes of Financial Exclusion (CFE)) are more than 0.05, which means that two variables have no statistically significant impact on the Effectiveness of Financial Inclusion (EFI), hence $\mathrm{H7}$, and $\mathrm{H} 11$ are not supported.

Table 7. Result of Multiple Linear Regression for Dependent Variable Effectiveness of Financial Inclusion

\begin{tabular}{|c|c|c|c|c|c|}
\hline \multirow{2}{*}{$\begin{array}{l}\text { Independent } \\
\text { Variable }\end{array}$} & \multicolumn{2}{|c|}{ Unstandardized Coefficients } & \multirow{2}{*}{$\begin{array}{c}\text { Standardized } \\
\text { Coefficients } \\
\text { Beta }\end{array}$} & \multirow{2}{*}{$\mathrm{t}$} & \multirow{2}{*}{ Sig. } \\
\hline & B & Std.Error & & & \\
\hline (Constant) & -1.112 & .844 & & -1.318 & . 188 \\
\hline Awareness of Financial Inclusion (AFI) & .052 & .039 & .023 & 1.332 & .184 \\
\hline Access and Usage of Financial Inclusion (AUFI) & .101 & .015 & .160 & 6.601 & $.000 * *$ \\
\hline Challenges of Financial Inclusion (CFI) & .635 & .024 & .683 & 25.944 & $.000 * *$ \\
\hline Impact of Financial Literacy (IFL) & .246 & .030 & .200 & 8.110 & $.000 * *$ \\
\hline Causes of Financial Exclusion (CFE) & .001 & .023 & .001 & .045 & .964 \\
\hline R Square & & & 0.865 & & \\
\hline Adjusted R Square & & & 0.864 & & \\
\hline
\end{tabular}




\section{Research Implication}

In this research study, the following suggestions are highlighted to improve the effectiveness of financial inclusion and rural upliftment in the state:

- The finding revealed that the rural citizens are highly appreciated and they felt that they are having a positive opinion on financial inclusion schemes. Financial Inclusion programme is supporting and make the citizen feel confident for making towards better result and make citizen engagement, citizen empowerment and rural upliftment through the social inclusion.

- The usage of financial inclusion schemes is found more among the middle-aged generation, thus it creates a constructive view in rural areas and provides new space for efficient use of such schemes in an effective manner.

- The awareness and usage of financial inclusion schemes is very low among the rural citizens belonging to the older generation because of low use, unawareness and misconception. Thus, steps must be taken to increase the awareness of rural citizens that such schemes depend on choice and the adoption is inevitable.

- The rural citizens are strongly associated and integrated with the financial inclusion scheme which would be other developmental and social welfare schemes. Financial inclusion programmes generate economic progress and prosperity that drive activities among the standard of living is increasing across all segments of the society.

- Hence, we need specific and active policies for increasing the financial inclusion scheme among the rural citizens in addition to the easy to access, citizen support and government schemes on finger tips.

- The government should address not only the accessibility and usage of financial inclusion but also take initiatives on increasing banking habits among rural area people through different programmes such as social media awareness program, periodical reviews and inspection by government officials and people's representatives.

- The government wants to conduct special camps where the citizens are ready to take the benefits of financial inclusion schemes but it will bring overall upliftment among the rural citizens. The government wants to appoint volunteers in the regional area to support the citizens in educating schemes related to financial inclusion, benefits about financial inclusion schemes and so on.

- This research is an eye opener for the stakeholders in the implementation of financial inclusion programme because of facts and information are given by the citizen.

\section{Conclusions}

Financial inclusion in the Tamil Nadu state and India as a whole is a dream which can be fulfilled by continuous efforts of the Government, financial institutions and citizens at large. There is no doubt that pan-India has significantly enhanced the financial inclusion of the marginalised sections towards increasing saving and investment patterns, independent transaction, business enablement, insurance to the general public at a lower premium cost and pension to the unorganized sectors to be reached to the ultimate beneficiary which belongs to entire nation. Financial inclusion programme is supporting all the citizens at different regions. Many suggestions and research findings are presented above, but this research study aims at understanding the effectiveness of financial inclusion and rural upliftment with empirical evidence from Tamil Nadu. Judgemental sampling is used as a sampling method in this research to obtain the research outcome. In this study, research constraints are sample size and sampling technique taken for this research is not sufficient to define all the citizens of Tamil Nadu. Hence, the results end with rural area citizens has a progressive opinion and involvement towards using the financial inclusion programme. This result shows that financial inclusion programme is potential and capable to transform the face of our state Tamil Nadu and it travels continuously towards upliftment of each and every individual without a doubt.

\section{Future Research Scope}

This Study focuses on effectiveness of financial inclusion and rural upliftment with empirical evidence from Tamil Nadu and sampling also done based on these respondents but in the future,

- Fintech is observed as the easy cum convenient option to penetrate in to rural areas, since the usage and coverage of telecommunication network enhances to utilize the available resources to the optimum level. Mobile based financial services through "app", "e-wallets" and digital platforms of various commercial and professional institutions are ease the progress of financial inclusion programme among the rural people.

- There is a possibility to enlarge the research area to whole nations and in-depth research in the state of Tamilnadu to get effective result on effectiveness of financial inclusion programme.

- In addition to this, future research may consider more dimensions of financial inclusion like perception, engagement, empowerment of citizens and comparative study on different financial inclusion scheme at different regions, as our study is restricted to only (rural upliftment) of financial inclusion. 


\section{REFERENCES}

[1] D. Ambarkhane, A.S. Singh, B. Venkataramani. Measuring Financial Inclusion of Indian States, International Journal of Rural Management, Vol. 12, No. 1, pp. 72-100, 2016.

[2] B. Thomas, P. Subhashree. Factors that Influence the Financial Literacy among Engineering Students, Procedia Computer Science, Vol. 172, pp. 480-487, 2020.

[3] S. Bawre, S. Kar. An investigation of the demographic factors affecting financial literacy and its components among urban Indians, Int. J. Education Economics and Development, Vol. 10, No. 4, pp. 398-426, 2019.

[4] D.K. Mishra, S. Malik, A. Chitnis, D. Paul, S.S. Dash. Factors Contributing to Financial Literacy and Financial Inclusion among Women in Indian SHGs, Universal Journal of Accounting and Finance, Vol. 9, No. 4, pp. 810-819, 2021. DOI: 10.13189/ujaf.2021.090427

[5] S. Bhatia, S. Singh. Empowering Women Through Financial Inclusion: A Study of Urban Slum, VIKALPA: The Journal for Decision Makers, Vol. 44, No. 4, pp. 182-197, 2019.

[6] R.K.P. Gutti. Assessing the Impact of Socio-Demographic Factors on Financial Literacy of PG Management students in Hyderabad, Psychology and Education, Vol. 57, No. 9, pp. 1653-1658, 2020.

[7] P. Manchanda, S. Sukhija. A Study on Factors affecting Financial Literacy among Working Women in Punjab, Journal of Emerging Technologies and Innovative Research, Vol. 6, No. 1, pp. 650-657, 2019.

[8] B. Krishnakumare, S. Singh. Assessing the Level of Financial Literacy among Rural Households of Tamil Nadu, Ann. Agric. Res. New Series, Vol. 40, No. 2, pp. 210-217, 2019.

[9] A.R. Khaki. Effectiveness of financial inclusion programs: a case study of Jammu and Kashmir state, Int. J. Financial Innovation in Banking, Vol. 2, No. 1, pp. 29-47, 2018.

[10] L.B. Dam, M. Hotwani. Financial Literacy: Conceptual Framework and Scale Development, SAMVAD: SIBM Pune Research Journal, Vol. 15, pp. 61-69, 2018.

[11] J. Jungo, M. Madaleno, A. Botelho. The Relationship between Financial Inclusion and Monetary Policy: A Comparative Study of Countries' in Sub-Saharan Africa and Latin America and the Caribbean, Journal of African Business, pp. 1-22, 2021.

[12] C. Rangarajan. Report of the Committee on Financial Inclusion, Reserve Bank of India, pp. 1-27, 2008.

[13] M. Sharma, M. Gulati. A Study of Financial Inclusion in India - Implementing Agencies and Stakeholders in Rajasthan, IIS University Journal of Commerce \& Management, Vol. 5, No. 1, pp. 96-113, 2016.

[14] S. Rastogi, C. Panse, A. Sharma, V.M. Bhimavarapu.

Unified Payment Interface (UPI): A Digital Innovation and Its Impact on Financial Inclusion and Economic Development, Universal Journal of Accounting and Finance, Vol. 9, No. 3, pp. 518-530, 2021. DOI: 10.13189/ujaf.2021.090326

[15] M. Gomathy. An Overview of Financial Inclusion and rural development in India, IOSR Journal of Business and Management, Vol. 17, No. 8, pp. 6-11, 2015.

[16] Y.K. Vaid, V. Singh, M. Sethi. Determinants of Successful Financial Inclusion in Low-Income Rural Population, The Indian Economic Journal, Vol. 68, No. 1, pp. 82-100, 2020.

[17] V. Amala, V. Akilessh. Financial Inclusion Program of Various South Indian Bank in a Selected 10 Villages, IOSR Journal of Business and Management, Vol. 17, No. 2, pp. 45-53, 2015.

[18] M. Bhuvana, S. Vasantha. Dimensions of Measuring Financial Inclusion in the Rural Areas of Tamil Nadu, Indian Journal of Science and Technology, Vol. 9, No. 32, pp. 1-8, 2016.

[19] M.M. Irshad, M. Shahid. A Theoretical Study on financial inclusion with reference to central government schemes of India, The Research Journal of Social Sciences, Vol. 10, No. 6, pp. 335-338, 2019.

[20] C.P. Koorse, S. Kavitha. A study on Banking Penetration in Financial Inclusion Wih Special Reference to Tamil Nadu, International Journal of Engineering and Management Research, Vol. 5, No. 1, pp. 37-44, 2015.

[21] M.S. Sibi, A.A. Ananth. Financial Inclusion: Role of Banking Services in Tamil Nadu, International Journal of Business and Administration Reserach Review, Vol. 2, No. 16, pp. 244-247, 2016.

[22] M. Jegadeeshwaran, M. Basuvaraj. A study on Analysis of Financial Inclusion in Tamil Nadu, A Journal Of Composition Theory, Vol. 13, No. 1, pp. 621-628, 2020.

[23] K.N. Usha, K. Hari. Impact of Self Help Groups Towards Financial Inclusion in Kancheepuram District of Tamil Nadu, International Journal of latest Engineering and Management Reserach, Vol. 2, No. 6, pp. 37-44, 2017.

[24] N. Murugan, T. Ravikumar, B. Suresha. Financial Products and Services Needs of People in Tamil Nadu, Journal of Research in Dynamical and Control Systems, Vol. 7, pp. 314-320, 2017.

[25] M. Mala, G. Vasanthi. Problems and Challenges of Indian Post in Financial Inclusion, International Journal of Interdisciplinary Research in Arts and Humanities, Vol. 1, No. 1, pp. 186-189, 2016.

[26] N. Sundaram, M. Sriram. Financial Inclusion Determinants - An Empirical Investigation in Rural Regions of Vellor District, Tamil Nadu, American International Journal of Reserach in Humanities, Arts and Social Sciences, Vol. 9, No. 2, pp. 110-114, 2015.

[27] P. Sujlana, C. Kiran. A Study on Status of Financial Inclusion in India, International Journal of Management Studies, Vol. 5, No. 2, pp. 96-104, 2018. 